\title{
SPECTRAL PROBLEMS ON COMPACT GRAPHS
}

\author{
S.I. Kadchenko ${ }^{1,2}$, S.N. Kakushkin ${ }^{1}$, G.A. Zakirova ${ }^{2}$ \\ ${ }^{1}$ Nosov Magnitogorsk State Technical University, Magnitogorsk, Russian Federation \\ ${ }^{2}$ South Ural State University, Chelyabinsk, Russian Federation \\ E-mail: kadchenko@masu.ru, kakushkin-sergei@mail.ru, zakirovaga@susu.ru
}

\begin{abstract}
The method of finding the eigenvalues and eigenfunctions of abstract discrete semibounded operators on compact graphs is developed. Linear formulas allowing to calculate the eigenvalues of these operators are obtained. The eigenvalues can be calculates starting from any of their numbers, regardless of whether the eigenvalues with previous numbers are known. Formulas allow us to solve the problem of computing all the necessary points of the spectrum of discrete semibounded operators defined on geometric graphs. The method for finding the eigenfunctions is based on the Galerkin method. The problem of choosing the basis functions underlying the construction of the solution of spectral problems generated by discrete semibounded operators is considered. An algorithm to construct the basis functions is developed. A computational experiment to find the eigenvalues and eigenfunctions of the Sturm - Liouville operator defined on a two-ribbed compact graph with standard gluing conditions is performed. The results of the computational experiment showed the high efficiency of the developed methods.
\end{abstract}

Keywords: perturbed operators; eigenvalues; eigenfunctions; compact graph; continuity conditions; Kirchhoff conditions.

1. Perturbed Operators on Compact Graphs. Recently, the methods of mathematical modelling began to play an important role in the study of the frequency-resonance characteristics of various technical devices described by linear dynamical systems and computer diagnostics of technical systems based on frequencies of natural oscillations. In this case, usually, mathematical model is direct or inverse spectral problem for Sturm Liouville's operators on geometric graphs. The methods for finding eigenvalues and eigenfunctions of abstract discrete semibounded operators defined on compact graphs are developed in the article.

Let $\mathbf{G}=\mathbf{G}(\mathbf{V}, \mathbf{E})$ be a finite associated oriented compact graph. Here $\mathbf{V}=\left\{V_{i}\right\}_{i=1}^{i_{0}}-$ set of vertices, $\mathbf{E}=\left\{E_{j}\right\}_{j=1}^{j_{0}}$ - set of edges. Suppose, that each edge $E_{j}$ has the length of $l_{j}>0$ and cross-sectional area $d_{j}>0$. On the edges $\mathbf{E}$ of the graph $\mathbf{G}$ we consider the operator

$$
T+P=\left(T_{1}+P_{1}, T_{2}+P_{2}, \ldots, T_{j_{0}}+P_{j_{0}}\right)
$$

acting in the Hilbert space

$$
H=L_{2}(\mathbf{G})=\left\{\mathbf{g}=\left(g_{1}, g_{2}, \ldots, g_{j_{0}}\right), g_{j} \in L_{2}\left(0, l_{j}\right), j=\overline{1, j_{0}}\right\}
$$

with the scalar product [1]

$$
(\mathbf{g}, \mathbf{h})=\sum_{j=1}^{j_{0}} d_{j} \int_{0}^{l_{j}} g_{j} h_{j} d x, \mathbf{g}, \mathbf{h} \in H .
$$


Here $T_{j}$ are discrete semibounded operators, and $P_{j}$ are bounded operators, defined in $L_{2}\left(0, l_{j}\right)\left(j=\overline{1, j_{0}}\right)$. We consider the boundary value problem

$$
\begin{gathered}
\left(T_{j}+P_{j}\right) u_{j}=\mu u_{j}, u_{j}=u_{j}\left(x_{j}\right), x_{j} \in\left(0, l_{j}\right), j=\overline{1, j_{0}}, \\
\left.\sum_{E_{k} \in E^{\alpha}\left(V_{s}\right)} d_{k} \frac{d u_{k}}{d x_{k}}\right|_{x_{k}=0}-\left.\sum_{E_{m} \in E^{\omega}\left(V_{s}\right)} d_{m} \frac{d u_{m}}{d x_{m}}\right|_{x_{m}=l_{m}}=0, \\
u_{i}(0)=u_{k}(0)=u_{m}\left(l_{m}\right)=u_{h}\left(l_{h}\right), \\
E_{i}, E_{k} \in E^{\alpha}\left(V_{s}\right), E_{m}, E_{h} \in E^{\omega}\left(V_{s}\right), \forall s \in \mathbb{N} .
\end{gathered}
$$

Let $E^{\alpha}\left(V_{s}\right)$ denote a set of edges with origin at the vertex $V_{s}$, and $E^{\omega}\left(V_{s}\right)$ - set of edges with an end at the vertex $V_{s}$. Conditions (2) mean that the flow through each vertex must be equal to zero, and (3) means that the solution $\mathbf{u}=\left(u_{1}, u_{2}, \ldots, u_{j_{0}}\right)$ at each vertex must be continuous. Also consider the boundary value problem:

$$
\begin{gathered}
T_{j} v_{j}=\lambda v_{j}, v_{j}=v_{j}\left(x_{j}\right), x_{j} \in\left(0, l_{j}\right), j=\overline{1, j_{0}}, \\
\left.\sum_{E_{k} \in E^{\alpha}\left(V_{s}\right)} d_{k} \frac{d v_{k}}{d x_{k}}\right|_{x_{k}=0}-\left.\sum_{E_{m} \in E^{\omega}\left(V_{s}\right)} d_{m} \frac{d v_{m}}{d x_{m}}\right|_{x_{m}=l_{m}}=0, \\
v_{i}(0)=u_{k}(0)=u_{m}\left(l_{m}\right)=u_{h}\left(l_{h}\right), \\
E_{i}, E_{k} \in E^{\alpha}\left(V_{s}\right), E_{m}, E_{h} \in E^{\omega}\left(V_{s}\right), \forall s \in \mathbb{N} .
\end{gathered}
$$

We denote by $\left\{\lambda_{k}\right\}_{k=1}^{\infty}$ eigenvalues of the problem (4) - (6), numbered in the order of nondecreasing of their magnitudes, and denote by $\left\{\mathbf{v}_{k}=\left(v_{1 k}, v_{2 k}, \ldots, v_{j_{0}, k}\right)\right\}_{k=1}^{\infty}-$ eigenvector-functions, corresponding to these eigenvalues $\lambda_{k}$. Approximate solution of the problem (1)-(3) can be found in the form

$$
\mathbf{u}(n)=\sum_{k=1}^{n} a_{k} \mathbf{v}_{k}
$$

where $a_{k}$, with undetermined coefficients and vector-functions $\mathbf{v}_{k}=\left(v_{1 k}, v_{2 k}, \ldots, v_{j_{0}, k}\right)$, form a countable basis in the space $L_{2}(\mathbf{G})$ with energy norm $\left\|\mathbf{v}_{k}\right\|_{T+P}$, induced by the energy scalar product

$$
\left(\mathbf{v}_{k}, \mathbf{v}_{m}\right)_{T+P}=\left((T+P) \mathbf{v}_{k}, \mathbf{v}_{m}\right)=\sum_{j=1}^{j_{0}} d_{j} \int_{0}^{l_{j}}\left(T_{j}+P_{j}\right) v_{j k} v_{j m} d x .
$$

The space $L_{2}(\mathbf{G})$ with energy norm $\left\|\mathbf{v}_{k}\right\|_{T+P}$ is denoted by $H_{T+P}$.

Theorem 1. If $T+P$ is a semibounded from below operator, acting in the Hilbert space $L_{2}(\mathbf{G})$, then solutions of the problem (4)-(6) form a basis in the energy space $H_{T+P}$.

Доказательство. The system $\left\{\mathbf{v}_{k}\right\}_{k=1}^{\infty}$ is a basis in the Hilbert space $H_{T+P}$ in that case, if it is closed in this space. Considering (4) and boundedness of operator $P$, we get

$$
\begin{aligned}
\left\|\mathbf{v}_{k}\right\|_{T+P}^{2}= & \left(\mathbf{v}_{k}, \mathbf{v}_{k}\right)_{T+P}=\left((T+P) \mathbf{v}_{k}, \mathbf{v}_{k}\right)=\left(T \mathbf{v}_{k}, \mathbf{v}_{k}\right)+\left(P \mathbf{v}_{k}, \mathbf{v}_{k}\right)= \\
=\left(\lambda_{k} \mathbf{v}_{k}, \mathbf{v}_{k}\right)+ & \left(P \mathbf{v}_{k}, \mathbf{v}_{k}\right)=\lambda_{k}\left\|\mathbf{v}_{k}\right\|^{2}+\left(P \mathbf{v}_{k}, \mathbf{v}_{k}\right) \leq \lambda_{k}\left\|\mathbf{v}_{k}\right\|^{2}+\left\|P \mathbf{v}_{k}\right\| \cdot\left\|\mathbf{v}_{k}\right\| \leq \\
& \leq \lambda_{k}\left\|\mathbf{v}_{k}\right\|^{2}+\|P\| \cdot\left\|\mathbf{v}_{k}\right\|^{2}=\left(\lambda_{k}+\|P\|\right) \cdot\left\|\mathbf{v}_{k}\right\|^{2} .
\end{aligned}
$$


The operator $T$ is positive defined in space $L_{2}(\mathbf{G})$. Denote by $H_{T}$ energy space, which is a replenishment of space $L_{2}(\mathbf{G})$ by the norm $\left\|\mathbf{v}_{k}\right\|_{T}$, induced by the energy scalar product, defined by the relation[2]:

$$
\left(\mathbf{v}_{k}, \mathbf{v}_{m}\right)_{T}=\left(T \mathbf{v}_{k}, \mathbf{v}_{m}\right)=\sum_{j=1}^{j_{0}} d_{j} \int_{0}^{l_{j}} T_{j} v_{j k} v_{j m} d x .
$$

Considering (4), we get, that $\left\|\mathbf{v}_{k}\right\|_{T}^{2}=\left(T \mathbf{v}_{k}, \mathbf{v}_{k}\right)=\lambda_{k}\left\|\mathbf{v}_{k}\right\|^{2}$, from whence

$$
\left\|\mathbf{v}_{k}\right\|^{2}=\frac{\left\|\mathbf{v}_{k}\right\|_{T}^{2}}{\lambda_{k}}
$$

Let $c$ be the lower bound of operator $T+P$. Then

$$
\left\|\mathbf{v}_{k}\right\|_{T+P}^{2}=\left((T+P) \mathbf{v}_{k}, \mathbf{v}_{k}\right) \geq c\left(\mathbf{v}_{k}, \mathbf{v}_{k}\right)=\frac{c}{\lambda_{k}}\left(T \mathbf{v}_{k}, \mathbf{v}_{k}\right)=\frac{c}{\lambda_{k}}\left\|\mathbf{v}_{k}\right\|_{T}^{2}
$$

Vector-functions $\mathbf{v}_{k}$ are eigenfunctions of operator $T$ and form a basis in $L_{2}(\mathbf{G})$ [1]. Therefore, the system of these functions is closed in $L_{2}(\mathbf{G})$, and hence, in $H_{T}$. Considering (8) - (10), we get

$$
\frac{c}{\lambda_{k}}\left\|\mathbf{v}_{k}\right\|_{T}^{2} \leq\left\|\mathbf{v}_{k}\right\|_{T+P}^{2} \leq\left(1+\frac{\|P\|}{\lambda_{k}}\right) \cdot\left\|\mathbf{v}_{k}\right\|_{T}^{2}
$$

Therefore, $H_{T+P}$ consists of the same element, that $H_{T}$, so that, the system of functions $\left\{\mathbf{v}_{k}\right\}_{k=1}^{\infty}$ is closed in $H_{T+P}$.

Corollary 1. Further, by the theorem 1, when solving the problem (1) - (3) in the form (7), we will use the first $n$ solutions of the problem (4) - (6) as coordinate functions $\mathbf{v}_{k}$, $(k=\overline{1, \infty})$. If necessary, the elements of the system $\left\{\mathbf{v}_{k}\right\}_{k=1}^{n}$ should be normalized.

In the articles of S.I. Kadchenko [3, 4] linear formulas for eigenvalues of perturbed discrete operators were obtained. Analogously to these papers, we can prove the theorem.

Theorem 2. If $T=\left(T_{1}, T_{2}, \ldots, T_{j_{0}}\right)$ is a discrete semibounded operator, and $P=$ $\left(P_{1}, P_{2}, \ldots, P_{j_{0}}\right)$ - bounded operator, acting in a separable Hilbert space $L_{2}(\mathbf{G})$, and the system of vector-functions $\left\{\mathbf{v}_{k}=\left(v_{1 k}, v_{2 k}, \ldots, v_{j_{0}, k}\right)\right\}_{k=1}^{\infty}$ forms an orthonormal basis in $L_{2}(\mathbf{G})$, then eigenvalues $\mu_{m}$ of operator $T+P$ can be found from formulas:

$$
\mu_{m}=\lambda_{m}+\sum_{j=1}^{j_{0}} d_{j} \int_{0}^{l_{j}} P_{j} v_{j m} v_{j m} d x+\delta(m) .
$$

Here $\delta(m)=\sum_{k=1}^{m-1}\left[\widehat{\mu}_{k}(m-1)-\widehat{\mu}_{k}(m)\right]$, and $\widehat{\mu}_{k}(m)-m$-th Galerkin's approximation of $k$-th eigenvalues.

Following the Galerkin method, coefficients $a_{k}(k=\overline{1, n})$, included in $(7)$, are found from the solution of a system of linear homogeneous equations

$$
\sum_{k=1}^{n} a_{k}\left[\left(\mathbf{v}_{k}, \mathbf{v}_{m}\right)_{T+P}-\mu\left(\mathbf{v}_{k}, \mathbf{v}_{m}\right)\right]=0 .
$$


Using the theorem 2, by the formulas (11) we find $n$ eigenvalues $\mu_{k}(k=\overline{1, n})$ of operator $T+P$. We substitute some $\mu_{m}$ into the system (12) instead of parameter $\mu$. Then the determinant of this system is equal to zero, and the system (12) will have nontrivial solutions. We denote the coefficients $a_{k}$, included in (7) and corresponding to this solutions, via $a_{k}^{(m)}(k=\overline{1, n})$. We use the normalization condition $\left(\mathbf{u}_{m}(n), \mathbf{u}_{m}(n)\right)=1$. Convert it, taking into account the system orthonormality $\left\{\mathbf{v}_{k}\right\}_{k=1}^{n}$ :

$$
\left(\mathbf{u}_{m}(n), \mathbf{u}_{m}(n)\right)=\sum_{k=1}^{n} \sum_{l=1}^{n} a_{k}^{(m)} a_{l}^{(m)}\left(\mathbf{v}_{k}, \mathbf{v}_{l}\right)=\sum_{l=1}^{n}\left(a_{l}^{(m)}\right)^{2}=1 .
$$

Having supplemented the system of equations (12) by equation (13), we find the coefficients $a_{k}^{(m)}(k=\overline{1, n})$.

2. Double-Edge Graph. As an example, consider a compact graph G, consisting of two edges $E_{1}$ and $E_{2}$ on Figure.

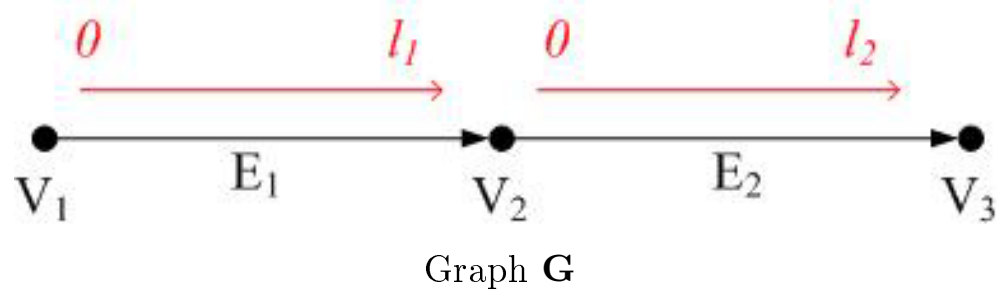

On each edge $E_{j}(j=\overline{1,2})$ we introduce the real parameter $x_{j}$, varying from 0 till $l_{j}$. On graph $\mathbf{G}$ define a vector-function $\mathbf{u}=\left(u_{1}, u_{2}\right)$, which component $u_{j}$ is a function of parameter $x_{j} \in\left[0, l_{j}\right]$, i.e. corresponds to an edge $E_{j}(j=\overline{1,2})$. On each edge $E_{j}$ of the graph $\mathbf{G}$ introduce an equation of the form:

$$
-u_{j}^{\prime \prime}+q_{j}\left(x_{j}\right) u_{j}=\mu u_{j}
$$

We will assume, that the components of vector-function $\mathbf{u}$ are interconnected by standard gluing conditions, including the condition (2), analogous to the Kirchhoff's condition, and continuity condition (3). The continuity condition means, that, since the vertex $V_{2}$ is an incident to the edges $E_{1}$ and $E_{2}$, then the values of the components of the vector-function $\mathbf{u}$ on these edges in the ends, corresponding to the vertex $V_{2}$, are coincide:

$$
u_{1}\left(l_{1}\right)=u_{2}(0)
$$

Condition (2) means that the sum of normal derivatives of the components of the vectorfunction $\mathbf{u}$ in the vertices $V_{j}(j=\overline{1,3})$ is equal to zero, i.e. if $V_{j}$ corresponding to $x_{j}=0$, then the derivative of the component $u_{j}$ in the point, corresponds to the vertex $V_{j}$, is taken with a sign "+", and with a sign "-", if $V_{j}$ corresponds to $x_{j}=l_{j}$ :

$$
-\left.\frac{d u_{1}}{d x_{1}}\right|_{x_{1}=l_{1}}+\left.\frac{d u_{2}}{d x_{2}}\right|_{x_{2}=0}=0
$$

In the boundary vertices $V_{1}$ and $V_{3}$ the conditions (2) transform to the Neumann's conditions:

$$
\left.\frac{d u_{1}}{d x_{1}}\right|_{x_{1}=0}=0
$$




$$
\left.\frac{d u_{2}}{d x_{2}}\right|_{x_{1}=l_{2}}=0
$$

We use the system of coordinate functions $\left\{\mathbf{v}_{k}\right\}_{k=1}^{n}$ to construct the solution of the problem (7), (14) - (18) and while finding the eigenvalues $\left\{\mu_{k}\right\}_{k=1}^{n}$ by the formulas (11). To find the system we solve the boundary value problem:

$$
\begin{gathered}
-v_{j}^{\prime \prime}=\lambda v_{j}, j=\overline{1,2} \\
v_{1}\left(l_{1}\right)=v_{2}(0), \\
-\left.\frac{d v_{1}}{d x_{1}}\right|_{x_{1}=l_{1}}+\left.\frac{d v_{2}}{d x_{2}}\right|_{x_{2}=0}=0 \\
\left.\frac{d v_{1}}{d x_{1}}\right|_{x_{1}=0}=0 \\
\left.\frac{d v_{2}}{d x_{2}}\right|_{x_{1}=l_{2}}=0
\end{gathered}
$$

It can be shown that eigenvalues of the spectral problem (19) are

$$
\lambda_{k}=\left(\frac{\pi k}{l_{1}+l_{2}}\right)^{2}
$$

and eigenfunctions are

$$
\begin{aligned}
& v_{1 k}\left(x_{1}\right)=C_{k} \cos \sqrt{\lambda_{k}} x_{1} \\
& v_{2 k}\left(x_{2}\right)=C_{k}\left[\cos \sqrt{\lambda_{k}} l_{1} \cos \sqrt{\lambda_{k}} x_{2}-\sin \sqrt{\lambda_{k}} l_{1} \sin \sqrt{\lambda_{k}} x_{2}\right] .
\end{aligned}
$$

The constants $C_{k}$ are determined from the normalization condition.

Through $\mathbf{v}_{k}=\left(v_{1 k}, v_{2 k}\right)$ denote the vector-functions corresponding to the eigenvalues $\lambda_{k}$. To find eigenvalues $\mu_{k}$ and vector-functions $\mathbf{u}_{k}$ of the boundary problem (14) - (18) a computational experiment was conducted. Verification of the spectral characteristics was performed by substituting them into the equation (14). The Table shows the norms of the left and right side of the equation (14) and the difference between them.

Conclusion. New algorithm for finding eigenvalues of abstract discrete semibounded operators on geometric graph is developed. Numerous computational experiments have shown high computational efficiency of the algorithm.

\section{References}

1. Bayazitova A.A. The Sturm - Liouville Problem on Geometric Graph. Bulletin of the South Ural State University. Series: Mathematical Modelling, Programming and Computer Software, 2010, no. 16 (192), issue 5, pp. 4-10. (in Russian)

2. Vlasova E.A., Zarubin V.S., Kuvyrkin G.N. Priblizhennyye metody matematicheskoy fiziki [Approximate Methods of Mathematical Physics]. Moscow, Bauman MSTU, 2004. 704 p.

3. Kadchenko S.I., Kakushkin S.N. The Numerical Methods of Eigenvalues and Eigenfunctions of Perturbed Self-Adjoin Operator Finding. Bulletin of the South Ural State University. Series: Mathematical Modelling, Programming and Computer Software, 2012, no. 27 (286), issue 13, pp. 45-57. (in Russian)

4. Kadchenko S.I. Numerical Method for the Solution of Inverse Problems Generated by Perturbations of Self-Adjoint Operators by Method of Regularized Traces. Vestnik of Samara State University. Natural Science Series, 2013, no. 6 (107), pp. 23-30. (in Russian) 
Values $\left\|(T+P) \mathbf{u}_{k}\right\|$ and $\left\|\mu_{k} \mathbf{u}_{k}\right\|$ of the boundary problem (14) - (18) calculated with parameters $l_{1}=1, l_{2}=2, q_{1}\left(x_{1}\right)=\sin \left(2 x_{1}+1\right)$ and $q_{2}\left(x_{2}\right)=x_{2}^{2}+3 x_{2}+2$

\begin{tabular}{|c|c|c|c|}
\hline$k$ & $\left\|(T+P) \mathbf{u}_{k}\right\|$ & $\left\|\mu_{k} \mathbf{u}_{k}\right\|$ & $\left\|(T+P) \mathbf{u}_{k}-\mu_{k} \mathbf{u}_{k}\right\|$ \\
\hline 1 & 10,4227164 & 9,1403925 & 1,2823239 \\
2 & 15,5409132 & 14,3518941 & 1,1890191 \\
3 & 23,0321518 & 22,0003709 & 1,0317808 \\
4 & 32,7097768 & 31,9689829 & 0,7407939 \\
5 & 44,5560760 & 43,9575040 & 0,5985720 \\
6 & 58,7018393 & 58,1884571 & 0,5133822 \\
7 & 75,1222924 & 74,7029771 & 0,4193153 \\
8 & 93,6696164 & 93,3045596 & 0,3650569 \\
$\ldots$ & $\ldots$ & $\ldots$ & $\ldots$ \\
18 & 400,5064008 & 400,3463671 & 0,1600337 \\
19 & 443,2899290 & 443,1407540 & 0,1491750 \\
20 & 488,2289128 & 488,0880478 & 0,1408650 \\
21 & 535,3685999 & 535,2323454 & 0,1362546 \\
22 & 584,7313253 & 584,6030267 & 0,1282986 \\
$\ldots$ & $\ldots$ & $\ldots$ & $\ldots$ \\
30 & 1058,4182713 & 1058,3240996 & 0,0941718 \\
31 & 1127,5178582 & 1127,4275559 & 0,0903023 \\
32 & 1198,7865687 & 1198,6994693 & 0,0870994 \\
33 & 1272,2515155 & 1272,1661447 & 0,0853708 \\
34 & 1347,9301120 & 1347,8479328 & 0,0821793 \\
\hline
\end{tabular}

Received Aprile 21, 2017

УДК 519.624.3

DOI: $10.14529 / \mathrm{mmp} 170314$

\section{РЕШЕНИЕ СПЕКТРАЛЬНЫХ ЗАДАЧ НА КОМПАКТНЫХ ГРАФАХ}

\section{С.И. Кадченко ${ }^{1,2}$, С.Н. Какушкин ${ }^{1}$, Г.А. Закирова}

${ }^{1}$ Магнитогорский государственный технический университет им. Г.И. Носова,

г. Магнитогорск

${ }^{2}$ Южно-Уральский государственный университет, г. Челябинск

Разработана методика нахождения собственных чисел и собственных функций абстрактных дискретных полуограниченных операторов, заданных на компактных графах. Получены линейные формулы, позволяющие с высокой вычислительной эффективностью вычислять собственные значения этих операторов, начиная с любого их номера, независимо от того, известны ли собственные значения с предыдущими номерами. Данные формулы решают проблему вычисления всех необходимых точек спектра дискретных полуограниченных операторов, заданных на геометрических графах. 
Собственные функции находятся на основе метода Галеркина. Рассмотрен вопрос выбора базисных функций, лежащих в основе построения решения спектральных задач, порожденных дискретными полуограниченными операторами, и приводится алгоритм их построения. Проведен вычислительный эксперимент по нахождению собственньх чисел и собственных функций оператора Штурма - Лиувилля, заданного на двухреберном компактном графе со стандартными условиями склейки. Результаты вычислительных экспериментов показали высокую эффективность разработанной методики.

Ключевые слова: возмущенные операторы; собственные числа; собственные функиии; компактный граф; условия непрерывности; условия Кирхгофа.

\section{Литература}

1. Баязитова, А.А. Задача Штурма - Лиувилля на геометрическом графе / А.А. Баязитова // Вестник ЮУрГУ. Серия: Математическое моделирование и программирование. 2010. - № 16 (192), вып. 5. - С. 4-10.

2. Власова, Е.А. Приближенные методы математической физики / Е.А. Власова, В.С. Зарубин, Г.Н. Кувыркин. - М.: Изд-во МГТУ им. Н.Э. Баумана, 2004. - 704 с.

3. Кадченко, С.И. Численные методы нахождения собственных чисел и собственных функций возмущенных самосопряженных операторов / С.И. Кадченко, С.Н. Какушкин // Вестник ЮУрГУ. Серия: Математическое моделирование и программирование. - 2012. № 27 (286), вып. 13. - С. 45-57.

4. Кадченко, С.И. Численный метод решения обратных задач, порожденных возмущенными самосопряженными операторами, методом регуляризованных следов / С.И. Кадченко // Вестник Самарского университета. Естественнонаучная серия. - 2013. - № 6 (7). C. $23-30$.

Сергей Иванович Кадченко, доктор физико-математических наук, профессор, кафедра «Прикладная математика и информатика», Магнитогорский государственный технический университет им. Г.И. Носова (г. Магнитогорск, Российская Федерация); кафедра «Уравнения математической физики», Южно-Уральский государственный университет (г. Челябинск, Российская Федерация), kadchenko@masu.ru.

Сергей Николаевич Какушкин, кандидат физико-математических наук, кафедра «Прикладная математика и информатика», Магнитогорский государственный технический университет им. Г.И. Носова (г. Магнитогорск, Российская Федерация), kakushkin-sergei@mail.ru.

Галия Амрулловна Закирова, кандидат физико-математических наук, доцент, кафедра «Уравнения математической физики», Южно-Уральский государственный университет (г. Челябинск, Российская Федерация), zakirovaga@susu.ru.

Поступила в редакцию 21 апреля 2017 г. 